\title{
From ligands to binding motifs and beyond; the enhanced versatility of nanocrystal surfaces
}

\author{
J. De Roo*, K. De Keukeleere, Z. Hens and I. Van Driessche* \\ Surface chemistry bridges the gap between nanocrystal synthesis and their applications. In this respect, the discovery of \\ complex ligand binding motifs on semiconductor quantum dots and metal oxide nanocrystals opens a gateway to new \\ areas of research. The implications are far-reaching, from catalytic model systems to the performance of solar cells.
}

\section{Introduction}

Nanocrystal (NC) synthesis has become a mature area of research. Nucleation and growth processes are increasingly well understood and the underlying reaction mechanisms are being unraveled. ${ }^{1-4}$ Currently, various shapes and compositions can be synthesized and patterns are emerging from the apparent randomness of synthetic procedures. ${ }^{5}$ This versatile nanocrystal library has spurred a great interest from the side of engineers and physicists to use nanocrystals as functional building blocks in devices. Hence the change of focus from mere synthesis to NC processing which includes dispersion of NCs, assembly, patterning, deposition, etc. However, all application oriented research encounters the same hurdle; the NC surface. ${ }^{6}$ Therefore, surface tuning and modification are imperative to use NCs. The surface is often capped by steric organic molecules (ligands), coordinating to surface atoms and hence providing both surface passivation - eliminating for example electronic trap states - and colloidal stability. ${ }^{7}$

Central to the understanding of the organic-inorganic interface in these hybrid structures is the coordination of the ligand's functional group to the surface atoms of a NC. Initially, two ligand classes were considered; L-type ligands (e.g., amine) ${ }^{8}$ and X-type ligands (e.g., chloride). ${ }^{9-11}$ As most NCs are dispersed in apolar solvents, the desorption of charged ligands is prohibited, hence the strong binding of X-type ligands. Although the first surface chemistry studies brought great insights, they were usually academic endeavors with moderate practical value. This recently changed with major developments in both the semiconductor and metal oxide nanocrystal field, where the discovery of more complex binding motifs ${ }^{12}, 13$ has led to new ligand exchange strategies ${ }^{12,} 14$ and novels concepts in catalysis, ${ }^{15}$ thereby bridging the gap between nanocrystal synthesis and application.

The aim of this frontier article is not to describe in detail every existing bridge from each nanocrystal to its applications but rather to provide the reader with the tools and theoretical background to build new bridges. We systematically highlight the chemical principles behind surface ligation and ligand exchange, using the covalent bond classification as a theoretical framework. Taking Xtype ligands as a basis, we introduce three universal binding motifs, $\mathrm{NC}\left(\mathrm{MX}_{\mathrm{n}}\right), \mathrm{NC}(\mathrm{X})_{2}$ and $\mathrm{NC}\left(\mathrm{EX}_{\mathrm{n}}\right)$. We argue that our understanding of the surface has improved up to a level where NCs can be considered model systems, useful for new research areas and ready for rational processing as functional building blocks in various applications such as solar cells, ${ }^{16}$ thermoelectrics, ${ }^{17}$ nanocomposites, ${ }^{18}$ etc.

\section{From Ligands to binding motifs}

The covalent bond classification (CBC) is an established concept in organometallic chemistry to classify molecules by identifying the number and types of bonds that surround an element of interest. ${ }^{19}$, 20 To omit any discussion about charge distribution, oxidation states and ionic character, the $\mathrm{CBC}$ treats every bond as a covalent 2center-2-electron interaction. As such, the $\mathrm{CBC}$ provides a general, consistent and unambiguous framework and was therefore adopted by the nanocrystal community to classify NC-ligand interactions. ${ }^{4,7}$, 14, 15, 21 Ligands are labelled as L-, X- or Z-type, depending on the number of electrons $(2,1$ or 0$)$ that the neutral ligand donates to the NC-ligand bond (Figure 1). Beware, metal nanocrystals can be easily compared to metal complexes but many other NCs are more complex and feature (at least) two different adsorption sites (surface metal atoms and nonmetal atoms). L-type ligands (lewis bases) are typically coordinating to surface metal atoms while Ztype ligands (lewis acids) are typically coordinating to surface nonmetal atoms (Figure 1). X-type ligands interact with either metal or nonmetal atoms, depending on the affinity. In apolar solvents, the total colloidal object (NC and ligand) is required to be uncharged and with that requirement in mind, we can construct different binding motifs, i.e., combinations of NC stoichiometries and ligand types.

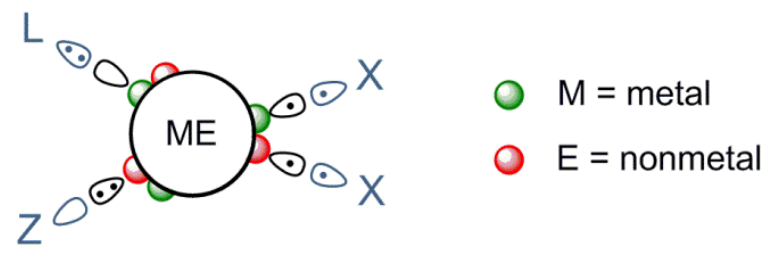

Fig. 1. Schematic representation of the covalent bond classification. X-type ligands are one-electron donors, L-type ligand are Lewis bases and Z-type ligands are Lewis acids. 


\section{$\mathrm{NC}\left(\mathrm{MX}_{\mathrm{n}}\right)$ and $\mathrm{NC}(\mathrm{Z})$}

In the case of excess metal (M) on the NC surface the dangling bonds are passivated by X-type ligands, leading to the $N C\left(M X_{n}\right)$ binding motif. A prime example of this binding motif is $\mathrm{CdSe}\left[\mathrm{Cd}(\mathrm{OOCR})_{2}\right]^{9,}, 22$ (Table 1), but also chlorides, ${ }^{10,17,23}$ iodides, ${ }^{16}$ phosphonates, ${ }^{10,24,25}$ thiolates ${ }^{26,27}$ and hydroxides ${ }^{28}$ were shown to coordinate to surface metal atoms as X-type ligands. Note that although these ligands are generally conceived as anions, the L-X-Z assignment applies to their neutral state. Indeed, neutral chlorine has one unpaired electron and neutral cadmium has two $5 \mathrm{~s}$ electrons. Upon the formation of the binding motif $\mathrm{CdSe}\left(\mathrm{CdCl}_{2}\right)$, cadmium and chlorine both donate one electron to each $\mathrm{Cd}-\mathrm{Cl}$ bond. The X-type ligand can be exchanged for another X-type ligand in a ligand exchange reaction, which can be written very concisely as

$$
\mathrm{NC}\left(\mathrm{MX}_{2}\right)+2 \mathrm{HX}^{\prime} \rightleftharpoons \mathrm{NC}\left(\mathrm{MX}_{2}^{\prime}\right)+2 \mathrm{HX}
$$

The exchange equilibrium will be determined by three factors: the difference in binding strength of the ligands, the acid base equilibrium and the difference in solubility of the free ligands. In principle, one could expect a lower binding strength for more acidic $\mathrm{HX}$ molecules since the corresponding base is less nucleophilic. However, it was demonstrated that acidic phosphonic acids ${ }^{25}$ (pKa $\approx$ 2.12 ) or hydrogen chloride ${ }^{17}$ ( $\mathrm{pKa} \approx-8$ ) can replace carboxylic acids ( $\mathrm{pKa} \approx 4.75$. This indicates that the proton transfer step can be the driving force of such exchange reactions, favoring binding of the most acidic ligand, especially in apolar solvents. The reaction can be reversed via the elimination of the proton transfer e.g., by providing an alkaline environment. Indeed, phosphonate ligands were stripped from CdSe NCs by a propionate salt, ${ }^{24,} 29$ and chloride ligands were exchanged for carboxylates on $\mathrm{HfO}_{2} \mathrm{NCs}$ by the addition of amines. ${ }^{13}$ On the other hand, thiolates were found to have a sufficiently high affinity for CdSe NCs to overcome the limitations of the proton transfer and thiols are able to displace carboxylic acids. ${ }^{27}$

Table 1. The different binding motifs and associated schematic representations and

\begin{tabular}{ll}
\hline Binding motif & Schematic presentation \\
$\mathrm{NC}\left(\mathrm{MX}_{\mathrm{n}}\right)$ & \multicolumn{1}{c}{ Examples } \\
$\mathrm{NC}(\mathrm{Z})$
\end{tabular}

examples.

Importantly, Owen et al. realized that the whole $\mathrm{MX}_{2}$ unit can also be regarded a Z-type ligand since cadmium carboxylate is a Lewis acid. ${ }^{12}$ The $\mathrm{Z} / \mathrm{MX}_{2}$ equivalence was confirmed for $\mathrm{CdS},{ }^{30} \mathrm{CdTe},{ }^{31}$ $\mathrm{PbSe}$ and $\mathrm{PbS}^{28}, 32 \mathrm{NCs}$ and profoundly changes the way the chemical stability of the ligand shell must be understood. Whereas X-type ligands are unable to desorb from a metal rich NC, the Z- ligands are potentially more labile. In the case of PbS NCs, lead oleate was shown to spontaneously desorb upon change of solvent polarity ${ }^{32}$ or dilution: ${ }^{30}$

$$
\mathrm{NC}\left(\mathrm{MX}_{2}\right) \rightleftharpoons \mathrm{NC}+\mathrm{MX}_{2}
$$

In contrast, the cadmium carboxylate capping is tightly bound to CdSe NCs. However, it was possible to displace this $\mathrm{Z} / \mathrm{MX}_{2}$-ligand by the addition of amines. Since amines are L-type ligands, they bind to the stoichiometric surface after this L-type promoted Z-type displacement (Figure 2): ${ }^{12}$

$$
\mathrm{NC}\left(\mathrm{MX}_{2}\right)+3 \mathrm{~L} \rightleftharpoons \mathrm{NC}(\mathrm{L})+\mathrm{MX}_{2} \mathrm{~L}_{2}
$$

The evaluation of the equilibrium constant associated with this displacement reaction ${ }^{\ddagger}$ can be used to assess the relative binding strength of Z-type ligands. ${ }^{31}$ From the decreased displacement at 60 ${ }^{\circ} \mathrm{C}$, the reaction was proposed to be exothermic. ${ }^{14}$ In addition, $\mathrm{MX}_{2}$ displacement restores the stoichiometry of the surface. Such precise control over surface stoichiometry enhanced the performance of photovoltaic cells, ${ }^{33}, 34$ revealed key factors determining the NC optical properties, ${ }^{35-37}$ and allowed the formation of a monolayer of connected (fused) quantum dots for opto-electronic applications. ${ }^{38-40}$ This demonstrates that the field has evolved from simply describing the reactivity at NC surfaces to actively using the surfaces as reagents in chemical reactions.

Direct Z-for-Z type exchanges have not yet been demonstrated as such. Nevertheless, it appears that the first step in some cation exchange reactions ${ }^{41-43}$ (e.g., the formation of CdS NCs from PbS $\mathrm{NCs}$ at elevated temperatures) is exactly this Z-for-Z exchange. On the other hand, Buhro et al. showed that cadmium oleate could be exchanged for zinc oleate on CdSe NCs by two successive steps. ${ }^{35}$ In the first step, $\mathrm{CdX}_{2}$ is displaced by amine ligands and after purification, $\mathrm{ZnX}_{2}$ is added to displace the amine ligands. This exchange of Z-type ligands could also be another way to realize the unfavorable exchange of X-type ligands, e.g., phosphonic acids for carboxylic acids, since the proton transfer step is again eliminated:

$$
\begin{aligned}
\mathrm{CdSe}\left[\mathrm{Cd}(\mathrm{OP}(\mathrm{OH}) \mathrm{R})_{2}\right]+\mathrm{Cd}(\mathrm{OOCR})_{2} \\
\rightleftharpoons \mathrm{CdSe}\left[\mathrm{Cd}(\mathrm{OOCR})_{2}\right]+\mathrm{Cd}(\mathrm{OP}(\mathrm{OH}) \mathrm{R})_{2}
\end{aligned}
$$

As judged from the examples, the $Z / M X_{n}$ equivalence was only demonstrated for II-VI and IV-VI quantum dots $(n=2)$ and our conjecture is that it might be different for higher valence metals since $M X_{3}$ and $M X_{4}$ units would cause significant steric hindrance around the surface metal center. For example palmitate was shown to bind to $\operatorname{InP~NCs},{ }^{44}$ but there is no available report on indium palmitate desorption. In addition, indium myristate was found unable to bind to stoichiometric InP NCs, in contrast to $\mathrm{Zn}$ or $\mathrm{Cd}$ oleate. ${ }^{45}$

To transfer NCs from apolar to polar solvents, Helms et al. presented a useful stripping reaction with a Z-type ligand $\left(\mathrm{BF}_{3}\right) .^{46}$ In general the reaction can be written as

$$
\mathrm{NC}\left(\mathrm{MX}_{2}\right)+\mathrm{Z} \rightleftharpoons \mathrm{NC}(\mathrm{MX})^{+}+(\mathrm{ZX})^{-}
$$

Via DOSY NMR, it was proven that the $(\mathrm{ZX})^{-}$complex (a Lewis adduct) is dynamically stabilizing the surface, quickly switching between a free and a bound state. Until the latter, most examples were discussed in nonpolar solvents and exhaustive surface chemistry studies in polar media are scarce. ${ }^{46-48}$ of course, the organic molecules are usually replaced by inorganic ions during phase transfer to polar media, rendering the classical ${ }^{1} \mathrm{H}$ solution NMR toolbox less useful and making the surface characterization a difficult task. A very careful study was presented by Kovalenko et 
al., elucidating the phase transfer of CdSe NCs from hexane to methyl formamide (MFA) with metal chalcogenide complexes by a combination of tin and proton NMR and theoretical calculations. ${ }^{47}$ These showed that the cadmium rich stoichiometry was retained during phase transfer, establishing the exchange reaction as

$$
\begin{aligned}
\mathrm{CdSe}\left[\mathrm{Cd}(\mathrm{OOCR})_{2}\right] & +\mathrm{K}_{6} \mathrm{Sn}_{2} \mathrm{~S}_{7} \\
& \rightleftharpoons 6 \mathrm{~K}^{+}+\mathrm{CdSe}\left[\mathrm{Cd}\left(\mathrm{Sn}_{2} \mathrm{~S}_{7}\right)\right]^{4-}+2(\mathrm{OOCR})^{-}
\end{aligned}
$$

In conclusion, the $\mathrm{NC}\left(\mathrm{MX}_{n}\right)$ binding motif shows reactivity towards $\mathrm{X}$-, L- and Z-type ligands, leading to a variety of ligand exchanges and displacements.

\section{$\mathrm{NC}(\mathrm{X})_{2}$}

In the case of stoichiometric, binary or multinary NCs, X-type ligands can occur in pairs, one binding to the surface metal atoms, the other to the surface nonmetal atoms, a binding motif denoted as $N C(X)_{2}$, see Table 1 . Such a pair of $X$-type ligands could, for example, result from a dissociated acid or a dissociated salt Established $\mathrm{NC}(\mathrm{X})_{2}$ systems include (i) dissociated carboxylic acids that bind strongly to metal oxide $\mathrm{NCs}, \mathrm{HfO}_{2}(\mathrm{H})(\mathrm{OOCR})^{13,14}$ and (ii) ion pairs that dynamically stabilize $\mathrm{CsPbBr}_{3}$ perovskite $\mathrm{NCs}$; $\mathrm{CsPbBr}_{3}\left(\mathrm{RNH}_{3}\right)(\mathrm{Br}) .^{49}$ The different behavior of carboxylic acids towards metal oxide $\mathrm{NCs}, \mathrm{NC}(\mathrm{X})_{2}$, compared to the other metal chalcogenides, $\mathrm{NC}\left(\mathrm{MX}_{2}\right)$, is attributed to the difference in basicity. ${ }^{13}$ This makes for a strong oxygen-hydrogen bond, which also explains why dissociated carboxylic acids do not spontaneously desorb, not even at high temperature $\left(130{ }^{\circ} \mathrm{C}\right)^{15}$ or in solvents with a higher dielectric constant such as chloroform. ${ }^{13}$ Also water is able to dissociate to metal oxides, ${ }^{15,50}$ with a binding motif $\mathrm{MO}_{2}(\mathrm{H})(\mathrm{OH})$.

Obviously, a pair of X-type ligands can be exchanged for another pair of X-type ligands. Alternatively, only the anionic X-type ligand could be exchanged, for example

$\mathrm{CsPbBr}_{3}\left(\mathrm{RNH}_{3} \mathrm{Br}\right)+\mathrm{RNH}_{3} \mathrm{Cl} \rightleftharpoons \mathrm{CsPbBr}_{3}\left(\mathrm{RNH}_{3} \mathrm{Cl}\right)+\mathrm{RNH}_{3} \mathrm{Br}$ Again, this is the first step in a convenient anion exchange reaction, transforming $\mathrm{CsPbBr}_{3} \mathrm{NCs}$ in $\mathrm{CsPbCl}_{3}{ }^{51,52} \mathrm{The} \mathrm{NC}(\mathrm{X})_{2}$ binding motif was only recently recognized and regarding ligand exchange, it opens a broad range of possibilities. We envisage ligand exchanges where, e.g., lithium is traded for hydrogen on the surface of metal oxide NCs:

$2 \mathrm{MO}_{2}(\mathrm{H})(\mathrm{RCOO})+\mathrm{Li}_{2} \mathrm{CO}_{3} \rightleftharpoons 2 \mathrm{MO}_{2}(\mathrm{Li})(\mathrm{RCOO})+\mathrm{CO}_{2}+\mathrm{H}_{2} \mathrm{O}$ Since a $N C(X)_{2}$ binding motif implicates that the pair of X-type ligands is charge neutral, this should allow for exchange reactions with neutral L-type ligands. ${ }^{13}$ Indeed, two equivalents of octylamine can displace one equivalent of oleic acid from $\mathrm{HfO}_{2} \mathrm{NCs}$, where the first is used to displace the dissociated carboxylic acid as an ion pair and the second binds to the NC surface:

$$
\mathrm{NC}(\mathrm{X})_{2}+2 \mathrm{~L} \rightleftharpoons \mathrm{NC}(\mathrm{L})+\left[(\mathrm{XL})^{+}(\mathrm{X})^{-}\right]
$$

Such a reaction, however, requires a large excess of L-type ligand and remains limited by the relative affinity for the NC surface. For example, alcohols are too weak to cause any noticeable displacement. A stronger driving force for displacement is the conversion of the displaced ligand into a non-coordinating species by the new ligand. As an example, amide formation promotes the displacement of oleic acid from $\mathrm{HfO}_{2} \mathrm{NCs}$ by octylamine at $130{ }^{\circ} \mathrm{C}$ (Figure 2a and 2b). a

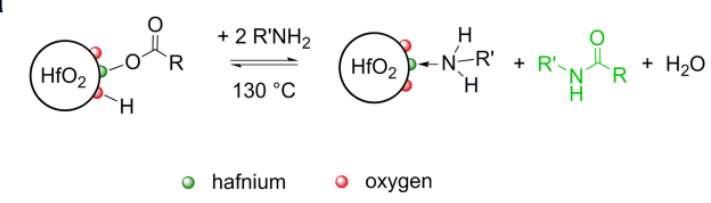

b
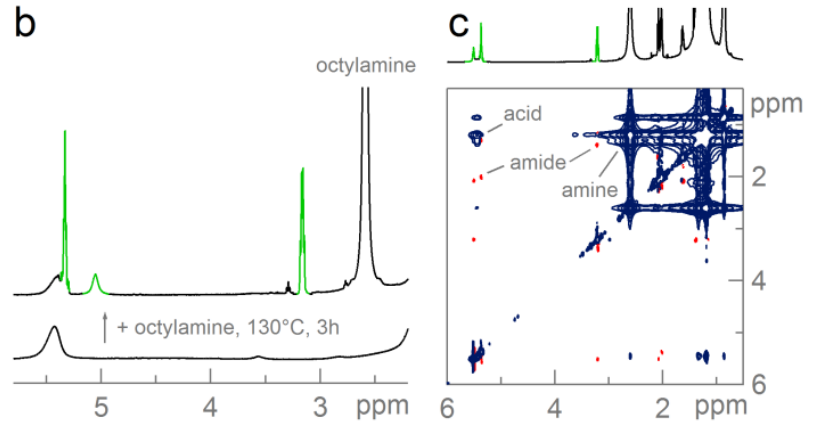

Fig. 2 (a) Tightly bound oleic acid is displaced by octylamine via the formation of an amide, (b) featuring sharp resonances in the ${ }^{1} \mathrm{H}$ NMR spectrum and (c) positive (red) cross peaks in the NOESY spectrum, thus proven it non-coordinating to the NC surface. Figure reproduced from ref. 11.

The amide does not interact with the $\mathrm{HfO}_{2}$ surface as attested by the positive (red) cross peaks in the NOESY NMR spectrum (figure 3c). This leaves a free adsorption site for the amine to bind to. The same strategy applies to alcohols, which displace acids by ester formation. ${ }^{15}$ This is a unique example where extremely weak alcohol ligands displace strongly binding carboxylic acids. One could write such a displacement reaction in a general format by representing a non-coordinating species as $\mathrm{Q}$.

$$
\mathrm{NC}(\mathrm{X})_{2}+2 \mathrm{~L} \rightleftharpoons \mathrm{NC}(\mathrm{L})+\mathrm{Q}
$$

This is very similar to powerful, irreversible stripping reactions, ${ }^{53,54}$ differing by the fact that here a new ligand is provided in situ and that the reaction proceeds under equilibrium control.

Since esters are actually valuable chemical products, it is interesting to go one step further and turn ligand displacement in a catalytic process. This is possible by adding excess of carboxylic acid which occupies a free adsorption site as soon as it is formed by esterification of a ligand, thereby closing the cycle. ${ }^{15}$ Importantly, this so-called sustained ligand displacement circumvents the traditional catalytic activity/colloidal stability trade-off in nanocatalysis. ${ }^{55,56}$

\section{$\mathrm{NC}\left(\mathrm{EX}_{\mathrm{n}}\right)$ and $\mathrm{NC}(\mathrm{L})$}

In the case of excess nonmetal (E) atoms on the NC surface (i.e., an anion rich core), dangling bonds might be passivated by X-type ligands, leading to a binding motif $\mathrm{NC}\left(\mathrm{EX}_{\mathrm{n}}\right)$. Whereas such a binding motif remains to be demonstrated in experiments, nothing prevents it from occurring and a made-up example could be $\mathrm{PbSe}\left[\mathrm{Se}\left(\mathrm{NRH}_{3}\right)_{2}\right]$. Note that the whole classification of binding motifs has perfect symmetry. Just like $\mathrm{NC}\left(\mathrm{MX}_{2}\right)=\mathrm{NC}(\mathrm{Z})$ is valid, we can also write $\mathrm{NC}\left(\mathrm{EX}_{2}\right)=\mathrm{NC}(\mathrm{L})$. For instance, adsorbed $\mathrm{H}_{2} \mathrm{~S}$ on $\mathrm{PbS}$ can be written as $\mathrm{PbS}\left(\mathrm{SH}_{2}\right)=\mathrm{NC}\left(\mathrm{EX}_{2}\right)=\mathrm{NC}(\mathrm{L})$.

L-type ligands are 2-electron-donors (Lewis bases) and typically form a dative bond to surface metal atoms of stoichiometric NCs, leading to a binding motif $\mathrm{NC}(\mathrm{L})$, see Table 1 . Examples include 
phosphines, $^{23}$ phosphine oxides ${ }^{24}$ and amines. ${ }^{8,} 57$ Although NC(L) systems were initially regarded as labile, there have been examples of amine ligands binding strongly to $\mathrm{Cu}$ or Zn containing NCs. ${ }^{57-60}$ This is not entirely surprising given the high affinity of amines for $\mathrm{Cu}$ and $\mathrm{Zn}$. L-type ligands can be replaced with other L-type ligands in a tit-for-tat exchange:

$$
\mathrm{NC}(\mathrm{L})+\mathrm{L}^{\prime} \rightleftharpoons \mathrm{NC}\left(\mathrm{L}^{\prime}\right)+\mathrm{L}
$$

These types of exchanges are usually limited in scope as the relative affinity for the surface determines the direction of the equilibrium. ${ }^{24}$ However, the L/EX 2 equivalence is important to consider since it opens the mind to new ligand exchange schemes.

\section{Outlook}

NC surface chemistry has grown into a well-developed subfield of nanoscience, complete with a suitable nomenclature. Therefore, colloidal NCs with a well-characterized core and surface are ready to serve as model systems in other fields of materials science. Supported NCs were already put forward as catalytic model systems ${ }^{61-63}$ but colloidal NCs are equally interesting platforms for catalysis. ${ }^{15,} 64$ Even more, NCs might also serve as model systems to understand the interaction of organic molecules with macroscopic, inorganic material, e.g., solid-state membranes or mesoporous materials. Such phenomena are usually impossible to detect with solution NMR methods. However, by downscaling the problem towards nanocrystals, solution NMR allows to assess the dynamics and interaction strength between organic molecules and the solid state. On the other hand, the surface of matter has been studied long before the first NC synthesis ${ }^{65}$ and the field of NC surface chemistry could certainly benefit from the insights offered by solid state studies. ${ }^{66}$ Hence the benefit of cross-pollination.

The NC model systems can also be used to revisit existing theories of NC nucleation and growth. The community has passed on the idea that oleic acid is the actual ligand and most probably cadmium oleate $^{12}$ is the primary ligand during CdSe synthesis. However, a lot of work remains to be done to translate the surface chemistry concepts as discussed here, from room temperature to temperatures relevant for NC synthesis. A rational synthesis strategy, replacing trial and error requires the thermodynamics of ligand binding to be understood. In addition, changes in the type of precursor might also influence the resulting surface chemistry. ${ }^{67}$ Finally, notwithstanding the large amount of elucidated NC surfaces, various aspects of systems such as metal oxides, III-V semiconductors, ternary and quaternary compounds remain to be addressed. However, the above framework and models should give guidance in the undertaking.

Finally, as-synthesized NCs are often ill-suited for their envisaged applications. NC processing is key and with a detailed knowledge of binding motifs, the surface chemistry can be precisely tailored to fit the application. Nanocomposites in polymers require miscibility of the NCs with the polymer precursor. ${ }^{68,69}$ On the other hand, fully inorganic nanocomposites require the dispersibility of NCs in highly polar matrix precursor solutions. ${ }^{18,} 48,70$ There is a wealth of ligand exchange strategies that offer transfer to polar solvents with very high dielectric constant like dimethylformamide. ${ }^{71-73}$ However, such solvents have considerable drawbacks such as toxicity and a high boiling point, hampering deposition via, e.g., spin coating. Solvents with lower boiling points but moderate dielectric constants (e.g. ethanol) hamper pure charge stabilization and only a limited number of strategies are available to transfer NCs to these solvents ${ }^{48,74,75}$ and more efforts are needed in this respect.

Regarding methodology, solution NMR has been identified as a major tool for studying surface attached ligands 76,77 and should become a standard technique in the nanocrystal field as it is in the field of organic synthesis. Indeed, NCs are hybrid objects and the organic part is equally important as the inorganic part. To study the inorganic or immobile organic part of the NC surface, solid state $\mathrm{NMR}^{78,} 79$ and in particular dynamic nuclear polarization surface enhanced $\mathrm{NMR}^{80}$ has proven very powerful. NMR has disadvantages though; (para)magnetic NCs are almost impossible to measure due to severe line broadening. Although High Resolution Magic Angle Spinning (HR-MAS) was claimed to recover signal intensity of ligands attached to iron oxide $\mathrm{NCs},{ }^{81}$ these results did not find wide acclaim. On the other hand, Isotherm Titration Calorimetry (ITC) is a well-known technique from biochemistry ${ }^{82}$ and was recently explored to study the thermodynamics of ligand binding to NCs. ${ }^{83-85}$ ITC might very well prove apt to probe the ligand dynamics of systems where NMR is blind. Another limitation of NMR spectroscopy is its need for sizeable ligands. Since protons close the surface have resonances broadened beyond recognition, a molecule should have protons far enough from the surface to contribute directly to the NMR spectrum. Since methyl moieties have more internal mobility than $\mathrm{CH}_{2}$ groups, a $\mathrm{CH}_{3}$ moiety can be located closed to the surface and still remain detectable. ${ }^{48}$ Alternatively, ligand binding can be indirectly demonstrated by competitive titration $^{48}$ or ligand exchange. ${ }^{86,87}$

\section{Conclusions}

The covalent bond classification has proven to be an extremely useful tool to organize the new binding motifs that were recently discovered. Even more, it allows to predict and to rationalize ligand exchange and ligand displacement reactions. Such an improved understanding has helped researchers to apply nanocrystals in the field of opto-electronics, photovoltaics and catalysis, to name a few. Although the surface chemistry of several semiconductors and metal oxide nanocrystals are currently well-understood, more efforts are needed to elucidate the ligand-NC interactions in the other materials of the NCs library and to use the acquired knowledge to steer chemical synthesis and control the nucleation and growth of NCs beyond the state of the art. The surface often sets as-synthesized nanocrystals apart from applications. This gap was recently bridged by knowledge of binding motifs that allows us not only to advance in the field of nanoscience but even to bring NCs into other research areas as intricate and well-controlled model systems.

\section{Acknowledgements}

We thank the Research Foundation Flanders (FWO) and Ghent University for financial support. We also thank Fabien Delpech, Vera Meynen and Emile Drijvers for interesting scientific discussions. 


\section{Notes and references}

¥ Note the difference between ligand exchange (binding motif remains the same) and ligand displacement (binding motif changes).

1. R. Garcia-Rodriguez, M. P. Hendricks, B. M. Cossairt, H. T. Liu and J. S. Owen, Chem. Mat., 2013, 25, 1233-1249.

2. M. D. Tessier, K. De Nolf, D. Dupont, D. Sinnaeve, J. De Roo and Z. Hens, J. Am. Chem. Soc., 2016, 138, 5923-5929.

3. H. T. Liu, J. S. Owen and A. P. Alivisatos, J. Am. Chem. Soc., 2007, 129, 305-312.

4. P. Reiss, M. Carrière, C. Lincheneau, L. Vaure and S Tamang, Chem. Rev., 2016, DOI: 10.1021/acs.chemrev.6b00116.

5. M. P. Hendricks, M. P. Campos, G. T. Cleveland, I. JenLa Plante and J. S. Owen, Science, 2015, 348, 1226-1230.

6. M. A. Boles, D. Ling, T. Hyeon and D. V. Talapin, Nat Mater, 2016, 15, 141-153.

$7 . \quad J$. Owen, Science, 2015, 347, 615-616.

8. B. Fritzinger, I. Moreels, P. Lommens, R. Koole, Z. Hens and J. C. Martins, J. Am. Chem. Soc., 2009, 131, 3024-3032.

9. I. Moreels, B. Fritzinger, J. C. Martins and Z. Hens, J. Am. Chem. Soc., 2008, 130, 15081-15086.

10. J. S. Owen, J. Park, P. E. Trudeau and A. P. Alivisatos, J. Am. Chem. Soc., 2008, 130, 12279-12280.

11. L. Cademartiri, J. Bertolotti, R. Sapienza, D. S. Wiersma G. von Freymann and G. A. Ozin, Journal of Physical Chemistry $B$ 2006, 110, 671-673.

12. N. C. Anderson, M. P. Hendricks, J. J. Choi and J. S. Owen, J. Am. Chem. Soc., 2013, 135, 18536-18548.

13. J. De Roo, F. Van den Broeck, K. De Keukeleere, J. C. Martins, I. Van Driessche and Z. Hens, J. Am. Chem. Soc., 2014 136, 9650-9657.

14. J. De Roo, Y. Justo, K. De Keukeleere, F. Van den Broeck, J. C. Martins, I. Van Driessche and Z. Hens, Angew. Chem.-Int. Edit., 2015, 54, 6488-6491.

15. J. De Roo, I. Van Driessche, J. C. Martins and Z. Hens, Nat Mater, 2016, 15, 517-521.

16. X. Lan, O. Voznyy, F. P. García de Arquer, M. Liu, J. Xu, A. H. Proppe, G. Walters, F. Fan, H. Tan, M. Liu, Z. Yang, S. Hoogland and E. H. Sargent, Nano Lett., 2016, DOI: 10.1021/acs.nanolett.6b01957.

17. M. Ibáñez, R. J. Korkosz, Z. Luo, P. Riba, D. Cadavid, S. Ortega, A. Cabot and M. G. Kanatzidis, J. Am. Chem. Soc., 2015 137, 4046-4049.

18. A. Llordes, G. Garcia, J. Gazquez and D. J. Milliron, Nature, 2013, 500, 323.

19. M. L. H. Green and G. Parkin, J. Chem. Educ., 2014, 91 807-816.

20. M. L. H. Green, J. Organomet. Chem., 1995, 500, 127 148 .

21. P. Bujak, Synth. Met., DOI: http://dx.doi.org/10.1016/j.synthmet.2016.04.002.

22. B. Fritzinger, R. K. Capek, K. Lambert, J. C. Martins and Z. Hens, J. Am. Chem. Soc., 2010, 132, 10195-10201.

23. N. C. Anderson and J. S. Owen, Chem. Mat., 2013, 25, 69-76.
24. J. T. Kopping and T. E. Patten, J. Am. Chem. Soc., 2008 130, 5689-5698.

25. R. Gomes, A. Hassinen, A. Szczygiel, Q. A. Zhao, A. Vantomme, J. C. Martins and Z. Hens, J. Phys. Chem. Lett., 2011, 2, 145-152.

26. X. Liu, M. Yu, H. Kim, M. Mameli and F. Stellacci, Nat Commun, 2012, 3, 1182.

27. R. R. Knauf, J. C. Lennox and J. L. Dempsey, Chem. Mat., 2016, DOI: 10.1021/acs.chemmater.6b01827.

28. D. Zherebetskyy, M. Scheele, Y. J. Zhang, N. Bronstein, C. Thompson, D. Britt, M. Salmeron, P. Alivisatos and L. W. Wang, Science, 2014, 344, 1380-1384.

29. A. J. Morris-Cohen, M. D. Donakowski, K. E. Knowles and E. A. Weiss, Journal of Physical Chemistry C, 2010, 114, 897906.

30. A. B. Nepomnyashchii, R. D. Harris and E. A. Weiss, Anal. Chem., 2016, 88, 3310-3316.

31. M. P. Campos and J. S. Owen, Chem. Mat., 2016, 28, 227-233.

32. R. Grisorio, D. Debellis, G. P. Suranna, G. Gigli and C. Giansante, Angewandte Chemie International Edition, 2016, DOI: 10.1002/anie.201511174, n/a-n/a.

33. D. K. Ko, A. Maurano, S. K. Suh, D. Kim, G. W. Hwang, J. C. Grossmann, V. Bulovic and M. G. Bawendi, ACS Nano, 2016, 10, 3382-3388.

34. G. H. Carey, A. L. Abdelhady, Z. J. Ning, S. M. Thon, O. M. Bakr and E. H. Sargent, Chem. Rev., 2015, 115, 12732-12763.

35. Y. Zhou, F. D. Wang and W. E. Buhro, J. Am. Chem. Soc., 2015, 137, 15198-15208.

36. M. M. Krause, L. Jethi, T. G. Mack and P. Kambhampati, J. Phys. Chem. Lett., 2015, 6, 4292-4296.

37. E. Busby, N. C. Anderson, J. S. Owen and M. Y. Sfeir Journal of Physical Chemistry C, 2015, 119, 27797-27803.

38. C. S. S. Sandeep, J. M. Azpiroz, W. H. Evers, S. C. Boehme, I. Moreels, S. Kinge, L. D. A. Siebbeles, I. Infante and A J. Houtepen, ACS Nano, 2014, 8, 11499-11511.

39. K. Whitham, J. Yang, B. H. Savitzky, L. F. Kourkoutis, F. Wise and T. Hanrath, Nat Mater, 2016, 15, 557-563.

40. W. Walravens, J. De Roo, E. Drijvers, S. Ten Brinck, E. Solano, J. Dendooven, C. Detavernier, I. Infante and Z. Hens, ACS Nano, 2016, DOI: 10.1021/acsnano.6b02562.

41. Y. Justo, L. K. Sagar, S. Flamee, Q. Zhao, A. Vantomme and Z. Hens, ACS Nano, 2014, 8, 7948-7957.

42. J. M. Pietryga, D. J. Werder, D. J. Williams, J. L. Casson, R. D. Schaller, V. I. Klimov and J. A. Hollingsworth, J. Am. Chem. Soc., 2008, 130, 4879-4885.

43. D. H. Son, S. M. Hughes, Y. Yin and A. Paul Alivisatos, Science, 2004, 306, 1009-1012.

44. A. Cros-Gagneux, F. Delpech, C. Nayral, A. Cornejo, Y Coppel and B. Chaudret, J. Am. Chem. Soc., 2010, 132, 1814718157.

45. J. L. Stein, E. A. Mader and B. M. Cossairt, The Journal of Physical Chemistry Letters, 2016, 7, 1315-1320.

46. S. E. Doris, J. J. Lynch, C. Y. Li, A. W. Wills, J. J. Urban and B. A. Helms, J. Am. Chem. Soc., 2014, 136, 15702-15710.

47. L. Protesescu, M. Nachtegaal, O. Voznyy, O Borovinskaya, A. J. Rossini, L. Emsley, C. Coperet, D. Gunther, E. 
H. Sargent and M. V. Kovalenko, J. Am. Chem. Soc., 2015, 137 1862-1874.

48. J. De Roo, S. Coucke, H. Rijckaert, K. De Keukeleere, D. Sinnaeve, Z. Hens, J. C. Martins and I. Van Driessche, Langmuir, 2016, 32, 1962-1970.

49. J. De Roo, M. Ibáñez, P. Geiregat, G. Nedelcu, W. Walravens, J. Maes, J. C. Martins, I. Van Driessche, M. V. Kovalenko and Z. Hens, ACS Nano, 2016, 10, 2071-2081.

50. R. Sato, S. Ohkuma, Y. Shibuta, F. Shimojo and S. Yamaguchi, The Journal of Physical Chemistry C, 2015, 119, 28925-28933.

51. Q. A. Akkerman, V. D'Innocenzo, S. Accornero, A. Scarpellini, A. Petrozza, M. Prato and L. Manna, J. Am. Chem. Soc., 2015, DOI: 10.1021/jacs.5b05602.

52. G. Nedelcu, L. Protesescu, S. Yakunin, M. I. Bodnarchuk, M. J. Grotevent and M. V. Kovalenko, Nano Lett., 2015, DOI: 10.1021/acs.nanolett.5b02404.

53. E. L. Rosen, R. Buonsanti, A. Llordes, A. M. Sawvel, D. J. Milliron and B. A. Helms, Angew. Chem.-Int. Edit., 2012, 51, 684689.

54. A. G. Dong, X. C. Ye, J. Chen, Y. J. Kang, T. Gordon, J. M. Kikkawa and C. B. Murray, J. Am. Chem. Soc., 2011, 133, 998 1006.

55. W. Huang, Q. Hua and T. Cao, Catal Lett, 2014, 144 1355-1369.

56. Z. Wu, D. E. Jiang, A. K. Mann, D. R. Mullins, Z. A. Qiao, L. F. Allard, C. Zeng, R. Jin and S. H. Overbury, J. Am. Chem. Soc. 2014, 136, 6111-6122.

57. Y. Coppel, G. Spataro, C. Pagès, B. Chaudret, A. Maisonnat and M. L. Kahn, Chemistry - A European Journal, 2012, 18, 5384-5393.

58. A. Shavel, M. Ibáñez, Z. Luo, J. De Roo, A. Carrete, M. Dimitrievska, A. Genç, M. Meyns, A. Pérez-Rodríguez, M. V. Kovalenko, J. Arbiol and A. Cabot, Chem. Mat., 2016, 28, 720726.

59. R. Dierick, F. Van den Broeck, K. De Nolf, Q. Zhao, A. Vantomme, J. C. Martins and Z. Hens, Chem. Mat., 2014, 26, 5950-5957.

60. C. N. Valdez, A. M. Schimpf, D. R. Gamelin and J. M. Mayer, ACS Nano, 2014, 8, 9463-9470.

61. M. Cargnello, C. Chen, B. T. Diroll, V. V. T. DoanNguyen, R. J. Gorte and C. B. Murray, J. Am. Chem. Soc., 2015, 137, 6906-6911.

62. M. Cargnello, V. V. T. Doan-Nguyen, T. R. Gordon, R. E. Diaz, E. A. Stach, R. J. Gorte, P. Fornasiero and C. B. Murray, Science, 2013, 341, 771-773.

63. Z. Niu and Y. Li, Chem. Mat., 2014, 26, 72-83.

64. S. Jansat, M. Gómez, K. Philippot, G. Muller, E. Guiu, C. Claver, S. Castillón and B. Chaudret, J. Am. Chem. Soc., 2004, 126, 1592-1593.

65. C. B. Murray, D. J. Norris and M. G. Bawendi, J. Am. Chem. Soc., 1993, 115, 8706-8715.

66. J. C. Thomas, D. P. Goronzy, K. Dragomiretskiy, D. Zosso, J. Gilles, S. J. Osher, A. L. Bertozzi and P. S. Weiss, ACS Nano, 2016, 10, 5446-5451.
67. K. De Keukeleere, J. De Roo, P. Lommens, J. C. Martins, P. Van der Voort and I. Van Driessche, Inorg. Chem., 2015, 54, 3469-3476.

68. G. Garnweitner, L. M. Goldenberg, O. V. Sakhno, M. Antonietti, M. Niederberger and J. Stumpe, Small, 2007, 3, 16261632.

69. C. Liu, T. J. Hajagos, D. Chen, Y. Chen, D. Kishpaugh and Q. Pei, ACS Appl. Mater. Interfaces, 2016, 8, 4795-4802.

70. P. Cayado, K. D. Keukeleere, A. Garzón, L. PerezMirabet, A. Meledin, J. D. Roo, F. Vallés, B. Mundet, H. Rijckaert, G. Pollefeyt, M. Coll, S. Ricart, A. Palau, J. Gázquez, J. Ros, G. V. Tendeloo, I. V. Driessche, T. Puig and X. Obradors, Superconductor Science and Technology, 2015, 28, 124007.

71. J. Huang, W. Y. Liu, D. S. Dolzhnikov, L. Protesescu, M. V. Kovalenko, B. Koo, S. Chattopadhyay, E. V. Shenchenko and D. V. Talapin, ACS Nano, 2014, 8, 9388-9402.

72. A. Nag, M. V. Kovalenko, J. S. Lee, W. Y. Liu, B. Spokoyny and D. V. Talapin, J. Am. Chem. Soc., 2011, 133, 1061210620.

73. D. N. Dirin, S. Dreyfuss, M. I. Bodnarchuk, G. Nedelcu, P. Papagiorgis, G. Itskos and M. V. Kovalenko, J. Am. Chem. Soc., 2014, 136, 6550-6553.

74. F. Rechberger, F. J. Heiligtag, M. J. Süess and M. Niederberger, Angewandte Chemie International Edition, 2014, 53, 6823-6826.

75. T. A. Cheema and G. Garnweitner, Crystengcomm, 2014, 16, 3366-3375.

76. Z. Hens and J. C. Martins, Chem. Mat., 2013, 25, 1211-

1221.

77. A. J. Morris-Cohen, M. Malicki, M. D. Peterson, J. W. J. Slavin and E. A. Weiss, Chem. Mat., 2013, 25, 1155-1165.

78. M. G. Berrettini, G. Braun, J. G. Hu and G. F. Strouse, J. Am. Chem. Soc., 2004, 126, 7063-7070.

79. L. E. Marbella and J. E. Millstone, Chem. Mat., 2015, 27, 2721-2739.

80. L. Piveteau, T.-C. Ong, A. J. Rossini, L. Emsley, C. Copéret and M. V. Kovalenko, J. Am. Chem. Soc., 2015, 137, 13964-13971.

81. L. Polito, M. Colombo, D. Monti, S. Melato, E. Caneva and D. Prosperi, J. Am. Chem. Soc., 2008, 130, 12712-12724.

82. J. E. Ladbury, Biotechniques, 2004, 37, 885-887.

83. C. Grote, K. J. Chiad, D. Vollmer and G. Garnweitner, Chem. Commun., 2012, 48, 1464-1466.

84. N. L. McFarlane, N. J. Wagner, E. W. Kaler and M. L. Lynch, Langmuir, 2010, 26, 6262-6267.

85. W. Lin, J. Walter, A. Burger, H. Maid, A. Hirsch, W. Peukert and D. Segets, Chem. Mat., 2014, 27, 358-369.

86. T. Pery, K. Pelzer, G. Buntkowsky, K. Philippot, H.-H. Limbach and B. Chaudret, ChemPhysChem, 2005, 6, 605-607.

87. M. H. Mobarok and J. M. Buriak, Chem. Mat., 2014, 26, 4653-4661. 